九州大学学術情報リポジトリ

Kyushu University Institutional Repository

Tree Diameter Distribution of Stands and Each Species in Largescale Cool-temperate Forest of Kyushu, Southern Japan

Kunisaki, Takashi

Laboratory of Forest Management, Faculty of Agriculture, Kyushu University

Imada, Morio

Laboratory of Forest Management, Faculty of Agriculture, Kyushu University

https://doi.org/10.5109/24129

出版情報：九州大学大学院農学研究院紀要. 41 (1/2)，pp.45-56，1996-11. Kyushu University バージョン：

権利関係 : 


\title{
Tree Diameter Distribution of Stands and Each Species in Large- scale Cool-temperate Forest of Kyushu, Southern Japan
}

\author{
Takashi Kunisaki and Morio Imada
}

\author{
Laboratory of Forest Management, Faculty of Agriculture, \\ Kyushu University, Fukuoka 812-81, Japan \\ (Received July 31, 1996)
}

\begin{abstract}
To elucidate size structure of cool-temperate forests of 1-10 ha order in Kyushu, southern Japan, DBH distribution was examined on semi-logarithmic scale, with reference to spatial scale, stratification and species composition. DBH distribution for 10ha-order forest (32.1'7 ha) showed a rotated sigmoid shape with a point of inflection at mid-DBH class and was composed of rotated sigmoid, concave and straight-shape distributions for older stands of lha-order. DBH distribution for stratification layer in 1 ha-order stands showed straight at understory and decreasing shape at mid- and overstory. And also, the size variation increased and the skewness decreased with upper stratification layer. In terms of tall tree species within 10 ha-order forest, the degree to which the DBH distribution show decreasing to rotated sigmoid shape was roughly related to the shade tolerance characteristics of each species. On the other hand, the shape of DBH distribution for low and small-tall tree species was thought to reflect not only the shade tolerance but also the sprouting characteristics.
\end{abstract}

\section{INTRODUCTION}

In Kyushu island of southern Japan, since large-scale natural forests had been converted to coniferous plantations till 1980s, the area of the natural forests had decreased sharply from year to year. Therefore, natural cool-temperate forests of Kyushu, in recent year, are quite important irrespective of primary or secondary forests, from the viewpoints of forest ecosystem, environmental resources and academic interests (Aragami, 1987; Yuruki and Setsu, 1992). In such situation, people should act to keep the balance between conservation and utilization of forest resources, and forest managers should plan forest management on which the mechanism and cycle of forest ecosystem are fully considered. Furthermore, development of silvicultural techniques for natural stands must be promoted to prevent deforestation or serious destroy of forest ecosystem due to intense disturbance such as large-scale clear-cutting (Ito and Aragami, 1993; The Kyushu University Forests, 1996). To solve these problems, forest researchers should analyze the structure of natural stands on the basis of adequate scientific approach and collect basic information for forest dynamics.

Diameter at breast height-tree density curve (hereafter, we say DBH distribution), one of the useful information for forest structure, has been examined since the last century (e.x. DeLiocourt, 1898; Hough, 1932; Meyer, 1952; Schmelz and Lindsey, 1965; Goff and West, 1975; Harcombe and Marks, 1978; West et al., 1981; Lorimer and Krug, 1983; Kohyama, 1986; Parker, 1988; Ishibashi, 1990). DeLiocourt (1898) was the first to describe the shape of DBH distribution for all-aged stands in publication. Meyer (1952) proposed a negative exponential distribution to describe inverse J-shaped distribution mathematically, and negative exponential distribution has been called "balanced 
distribution" in uneven-aged stands (Meyer, 1952; Knuchel, 1953). However, because the shape of DBH distribution for uneven-aged stands often changes due to the influence of spatial scale (stand area), development stage and species composition of stands (Goff and West, 1975; West et al., 1981; Ishibashi, 1990), the deviations from negative exponential distribution do not necessarily indicate "unbalanced" condition. Therefore, DBH distribution should be analyzed in relation to above-mentioned factors, to understand the structure of stands properly.

In Japan, DBH distributions for a large number of natural uneven-aged stands of 0.01-0.1 ha order have been examined (e.x. Kikuzawa and Asai, 1979; Aiba et al., 1983; Kikuzawa, 1984; Ninomiya et al., 1985; Kohyama, 1986; Higo et al., 1987; Komiyama, 1989; Ishibashi, 1990; Yuruki and Setsu, 1992; Ito and Aragami, 1993; Wada and Nakagoshi, 1994; Kunisaki and Imada, 1996). However, few DBH distributions for 1-10 ha order stands which are approximately equal to the area of sub-compartment have been reported until now (Suzuki, 1984; Higo and Teramoto, 1989; Tanouchi and Yamamoto, 1991; Wada and Nakagoshi, 1994). The objective of this paper is to elucidate the size structure of large-scale cool-temperate forests of 1-10ha order in central Kyushu, and we analyze the DBH distributions in relation to spatial scale, stratification and species composition of stands.

\section{STUDY SITE AND METHODS}

\section{Study site}

The Kyushu University Forest in Miyazaki (UFM) is located at mountainous area of central Kyushu, Japan (2916ha; 32" 22'10"N, 131" 10'40"E) and over cool-temperate deciduous forest zone. The altitudinal range is from 700-1476 m a.s.1.. Annual precipitation is about $3319 \mathrm{~mm}$ and this region is one of the most famous rain region in Japan. Therefore, debris flow, landslip and landslide induced by heavy rain have often occurred in UFM (The Kyushu University Forests, 1996). The average annual temperature is $13.1{ }^{\circ} \mathrm{C}$ at an elevation of $600 \mathrm{~m}$; the mean monthly maximum temperature is greatest in August $\left(23.6^{\circ} \mathrm{C}\right)$ and the mean monthly minimum temperature is lowest in January $\left(2.7^{\circ} \mathrm{C}\right)$. The soils are mainly brown forest soils. In addition, since UFM is located at mountainous area, strong wind usually blows and there are a lot of winddamaged trees on slope from $\mathrm{W}$-to $\mathrm{N}$-facing and ridge (The Kyushu University Forests, 1996).

The vegetation is regarded as Fagus crenata-Sasa borealis association (The Kyushu University Forests, 1996). Hardwood of Fagus crenata, Quercus mongolica var. grosseserrata and Betula grossa and softwood of Abies firma, Tsuga sieboldii and Pinus densiflora generally dominate the overstory. The understory is generally characterized by shade-tolerant low trees of Clethra barbinervis, Lindera triloba, Illicium religiosum and Pieris japonica and bamboo grass of Sasa borealis.

\section{Methods}

During the years 1985-1987, ten cutting blocks of natural secondary stands (a total area of $32.17 \mathrm{ha}$ ) in the Oyabu river basin of UFM were investigated for each tree $\geq 10 \mathrm{~cm}$ 
in DBH. Species or species group name, DBH and tree height were recorded in the yield inventory. In this paper, hereafter, the term of "forest level" indicates a total of the cutting block stands, and "block stand level" indicates each cutting block stand.

We employed Weibull distribution function $\left(f_{u}(D)\right)$ to describe the degree of skewness for DBH distributions :

$$
\left.f_{u}(D)=\left(c_{u} / \mathrm{b}_{w}\right)\left(\left(D-a_{w}\right) / b_{w}\right){ }^{c w}{ }^{1} \operatorname{EXP}\left(-\left(\left(D-a_{w}\right) / b_{w}\right)\right)^{c w}\right),
$$

where D is DBH, a, $(\mathrm{cm})$ minimal $\mathrm{DBH}, b_{u}(\mathrm{~cm})$ the positive parameter for cumulative distribution at the $63 \%$ point and $\mathrm{c}$, the positive parameter of the shape of distribution (Kakihara, 1995). This function can flexibly express the shape of any unimodal distribution (Bailey and Dell, 1973; Lorimer and Krug, 1983; Kakihara, 1995). The values of $c_{u} \leq 1$ indicate inverse-J shape, $1<c_{u}<3.6$ positively-skewed shape, $c_{u}=3.6$ approximately bell shape, and $c_{u}>3.6$ negatively-skewed shape of size distribution. The parameters of eq. (1) were obtained using a simple method which use mean and standard deviation of size distribution, and the values of gamma function (Kakihara, 1995).

We also employed a modified exponential distribution $(f(D))$ to describe the shape of DBH distribution (Minowa and Hirata, 1993):

$$
f(D)=\operatorname{EXP}\left(a D^{3} / 3+b D^{2} / 2+c D+d\right)
$$

where $\mathrm{a}, b, \mathrm{c}$ and $\mathrm{d}$ are parameters. This equation can flexibly express the shape of not only unimodal distributions but also such distributions as bimodal and rotated sigmoid (Minowa and Hirata, 1993). The parameters of eq. (2) were obtained using the ordinary multiple regression methods. In this paper, the shape of DBH distribution was judged from the sign (positive or negative) of four parameters, the value of $b / 2 a$ (a point of inflection) in eq. (2) and drawn graphs. Each DBH distribution on semi-logarithmic scale was assigned to one of five categories: negative exponential, concave, convex, rotated sigmoid and decreasing. First three categories are equal to inverse-J shape of the distribution on ordinary scale. The rotated sigmoid distribution has a plateau at mid-DBH range with a point of inflection (Goff and West, 1975; West et al., 1981). The decreasing distribution has a large number of stems in small or mid-DBH range, but with few stems in minimal DBH class (Parker, 1988).

The shape of DBH distribution was analyzed in relation to spatial scale (stand area), stratification and species composition. From a viewpoint of spatial scale, DBH distributions for all species at forest (32.17 ha) and block stand levels (1.56-5.38 ha) were examined. Stratification was divided into three layers: overstory $(14 \mathrm{~m}$ or more in tree height), midstory (from 9-13 m) and understory ( $8 \mathrm{~m}$ or less), and the DBH distributions for each layer of the block stands were examined. Also, DBH distributions for the major 22 species with high density were examined at forest level.

\section{RESULTS AND DISCUSSION}

The coefficients of determination for eq. (2) fit to the observed data were: from 0.95-0.99 for the forest (all block stands) and each block stand; from 0.58-0.99 for each stratification layer of the block stands; from 0.89-0.99 for each species at forest level. These results indicated that eq. (2) was well-fitted to the observed data. 


\section{DBH distributions in relation to spatial scale}

DBH distribution for all species at forest level was rotated sigmoid-shaped with a point of inflection at $48 \mathrm{~cm}$ class in $\mathbf{D B H}$ on the basis of the number of trees on logarithmic scale (hereafter, we say ln number) (Fig. 1). On the other hand, DBH distributions for all species at block stand level were assigned to three of five categories: rotated sigmoid, concave and negative exponential shapes (Table 1, Fig. 2). In other

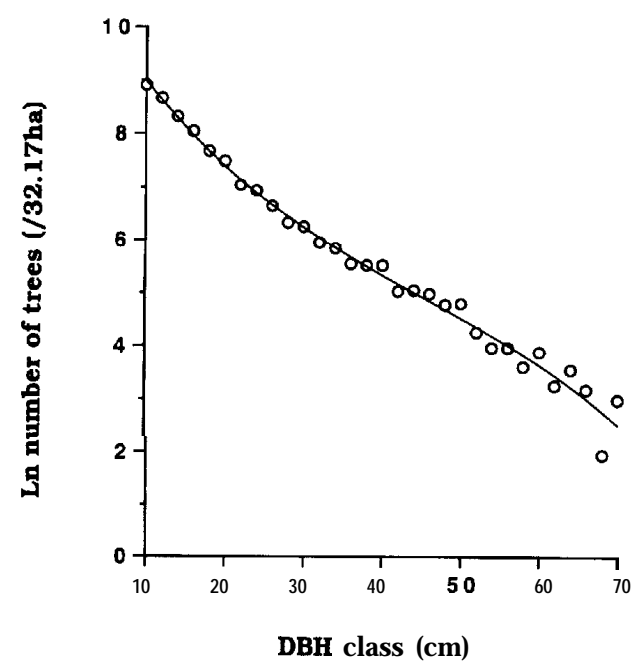

Fig. 1. DBH distribution for all species at forest level.

Ln number indicates the number of trees on logarithmic scale. Data of $2 \mathrm{~cm}$ interval DBH class. Fitted lines, by eq. 2 .

Table 1. Attributes of each cutting block stand

\begin{tabular}{ccccccc}
\hline Stand No. & $\begin{array}{c}\text { Area } \\
\text { (ha) }\end{array}$ & $\begin{array}{c}\text { Volume } \\
\left(\mathrm{m}^{3} / \mathrm{ha}\right)\end{array}$ & $\begin{array}{c}\text { Density } \\
(\text { No.ha })\end{array}$ & $\begin{array}{c}\text { Maximal height } \\
(\mathrm{m})\end{array}$ & $\begin{array}{c}\text { Shape parameter } \\
C_{\prime \prime}\end{array}$ & DBH curve form \\
\hline 1 & 1.76 & 206.1 & 710 & 20 & 0.93 & Sigmoid \\
2 & 1.56 & 180.4 & 874 & 20 & 0.89 & Sigmoid \\
3 & 2.53 & 134.5 & 856 & 20 & 0.87 & Sigmoid \\
4 & 1.57 & 122.5 & 930 & 18 & 0.91 & Sigmoid \\
5 & 4.65 & 125.7 & 932 & 21 & 0.85 & Concave \\
6 & 5.38 & 171.4 & 1136 & 21 & 0.71 & Concave \\
7 & 2.51 & 166.6 & 890 & 21 & 0.85 & Concave \\
8 & 4.31 & 173.5 & 686 & 22 & 0.91 & Concave \\
9 & 3.40 & 152.4 & 917 & 22 & 1.00 & N.E. \\
10 & 4.50 & 282.9 & 1317 & 23 & 0.94 & N.E. \\
\hline
\end{tabular}

* : negative exponential 


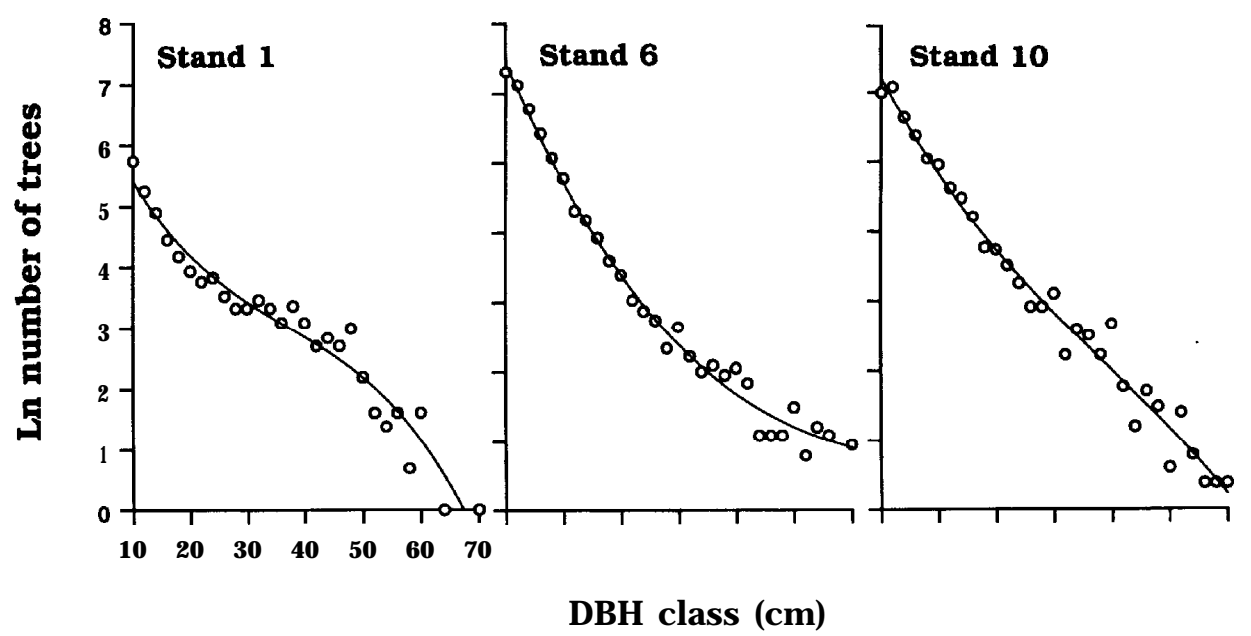

Fig. 2. DBH distributions for all species at block stand level. Fitted lines, by eq. 2 .

word, the rotated sigmoid distribution at forest level was constituted from four rotated sigmoid, four concave and two negative exponential distributions at block stand level. West et al. (1981) analyzed DBH distribution for all species of cool-temperate deciduous forests at regional level and found that the distribution had a concave structure modified slightly at mid-diameter classes by a component input of older stands containing rotated sigmoid distribution. They suggested that the degree to which the regional DBH distribution shows a negative exponential or rotated sigmoid shape is likely to reflect the age distribution in the region, and that the regional distribution showing a concave to rotated sigmoid shape would indicate a large proportion of older stands within the region (West et al., 1981). Here, we tried to apply this hypothesis to the objective forest. In the Oyabu river basin of UFM, the age structure of canopy trees of various secondary forest stands has been investigated (Setsu, 1990; Yuruki and Setsu, 1992; Kunisaki and Imada, 1996), and the average age of canopy trees of secondary stands in UFM where canopy height is more than $18 \mathrm{~m}$ was roughly estimated to 100 -year old or more (Ito and Aragami, 1993). This information suggested that the objective forest in this paper would have been organized by older block stands (Table 1). Therefore, the result that DBH distribution at forest level was a rotated sigmoid-shaped was thought to support the hypothesis proposed by West et al. (1981).

In plot stands of 0.01-0.1 ha order (hereafter, we say small-scale stand), such shape distributions as bimodal and multimodal were often found (e.x. Hough, 1932; Knuchel, 1953; Parker, 1988; Ishibashi, 1990; Yuruki and Setsu, 1992; Wada and Nakagoshi, 1994; Kunisaki and Imada, 1996). In these small-scale stands, interaction between overstory and understory, such as asymmetric competition for light, appears clearly. Thus, the shape of the distributions in small-scale stands indicates the degree of development of 
vertical structure or size hierarchy in tree community (Wada and Nakagoshi, 1994; Kunisaki and Imada, 1996). However, when some small-scale stands are treated as a single unit (block stand), the size structure of these small-scale stands is averaged and the resulting DBH distribution (at block stand level) would be a concave to rotated sigmoid shaped (Meyer, 1952; Goff and West, 1975).

\section{DBH distributions in relation to stratification}

Figure 3 shows DBH distributions for each stratification layer of the three block stands, Stand-1, Stand-6 and Stand-10 which show rotated sigmoid, concave and negative exponential shape, respectively (Fig. 2). The shape of DBH distributions for understory and midstory was respectively similar among these stands, though the DBH ranges varied. On the other hand, the shape of distributions for overstory was different among the three stands. For Stand-l, the number of trees on logarithmic scale remained constant irrespective of increasing DBH by $50 \mathrm{~cm}$, and then decreased sharply. For Stand-6 ln number increased with DBH by $20 \mathrm{~cm}$, and then decreased very gradually. For Stand-lo, In number increased with DBH by $30 \mathrm{~cm}$, and then decreased sharply. In addition, Stand$1 \mathrm{had}$ the more number of overstory $(32.5 \%$ of total number) and the greater ratio of coniferous trees in overstory $(83.0 \%)$ than those of the stands showing the other shape distributions. Stand-6 had the less number of overstory $(6.7 \%)$ than that of the other stands. These results suggest that the number ratios of overstory in stands and coniferous trees in overstories may influence the shape of $\mathrm{DBH}$ distributions for all species of stands (Goff and West, 1975), although the more critical investigations need to be conducted.

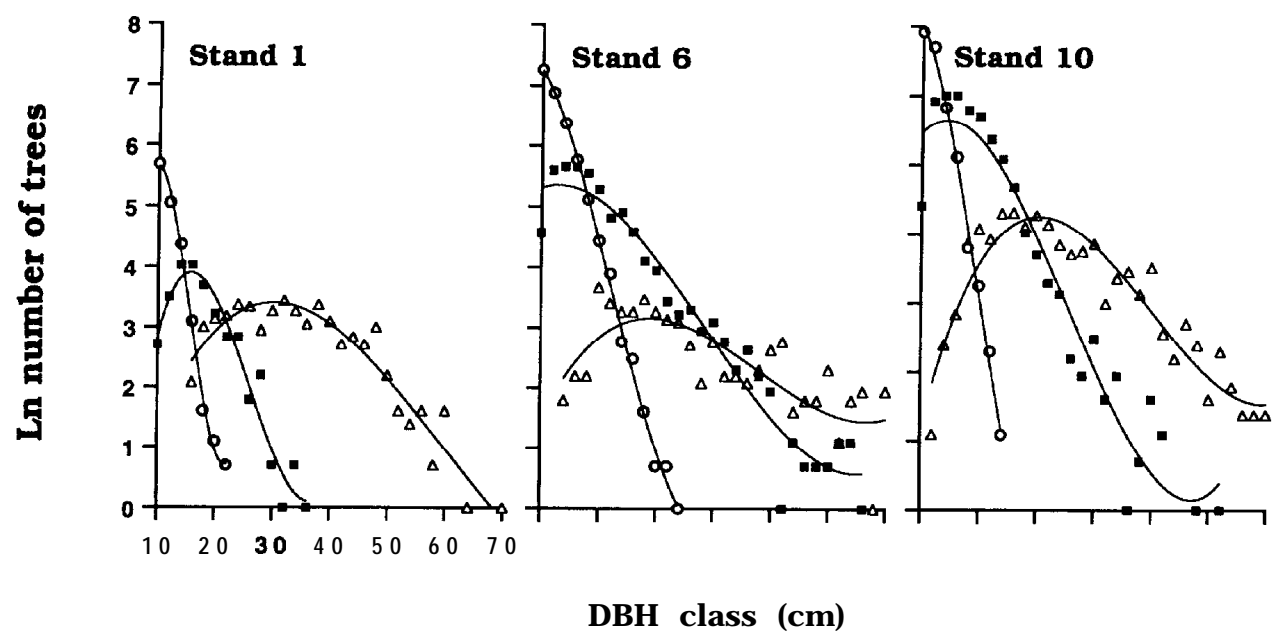

Fig. 3. DBH distributions for each stratification at block stand level. Circle, square and triangle represent understory, midstory and overstory of cutting block stand, respectively. Fitted lines, by eq. 2 . 


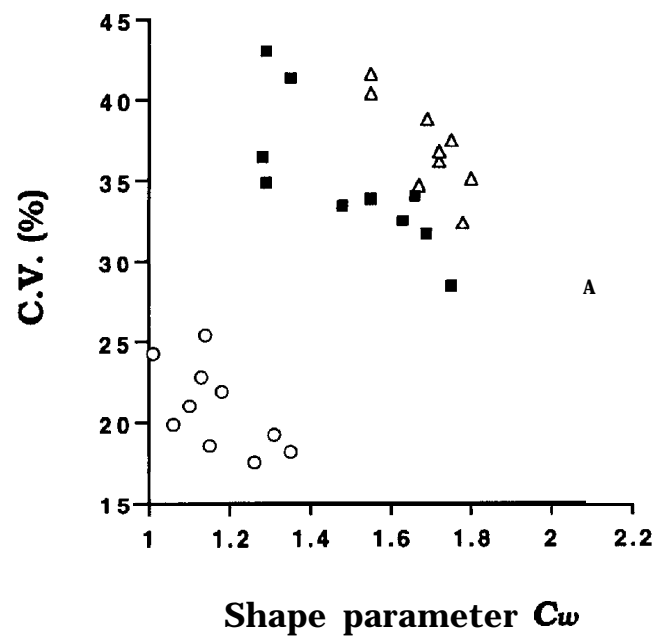

Fig. 4. Relationships between shape parameter $c$, and coefficient of variation for each stratification at block stand level.

Symbols are the same as those of Fig. 3.

Relationships between $c_{w}$ and coefficient of'variation (C.V.) for stratification layer transited right-upward on coordinates with increasing height class (Fig. 4). For each layer, C.V. decreased with increasing c,: size variation for each layer became less with decreasing the skewness of DBH distributions. It was supposed that the changes in size variation and skewness with increasing height class would be induced by such factors as life forms, development stage of each layer and competition among trees for light resource. In understory, there are a lot of low, small-tall and small-sized tall trees. These trees are intensely suppressed by mid- and overstory trees, and the resulting distributions would have a extremely large number of trees at minimal DBH class. On the other hand, overstory are occupied by matured and developing tall trees. These trees have accumulated the effects of competition for light on the tree size. Competition effect often appears as greater biomass allocation to height growth at the expense of DBH growth for some trees in secondary stands (Kunisaki et al., 1996): trees try to keep a given same height within canopy layer for survive. Thus, DBH growth greatly varies among trees of different species, age and crown size and the resulting DBH distributions would have a wide-ranged and less positively skewed shape.

\section{DBH distributions for each species}

Figure 5 and Table 2 show DBH distribution for each species at forest level and the attributes, respectively, Tall tree species, whose matured trees have more height than $15 \mathrm{~m}$ and usually grow up to the canopy layer of stands, were assign to all of five categories. Only Csp. (full name of each species was shown in Table 2) was a negative 
exponential-shaped, and $\mathrm{Qm}$ and $\mathrm{Bg}$ which are two of the most major canopy species of hardwood in UFM showed concave shape. These three species had approximately the same skewness $\left(c_{w}=1.01-1.06\right)$. Sm, As and Psp. with low shade tolerance were convexshaped and the values of $c_{w}$ were from 1.17-1 .39, which indicated less positive-skewed distribution than that of above-three species. Ts, Af, Asp. and Fc which are shadetolerant species and Mo which is a relatively shade-intolerant species showed rotated sigmoid-shape with $c_{w}$ from 0.91-1.26. Cac and Pd which are remarkably shade-intolerant species and Coc with a relatively medium shade tolerance were decreasing-shaped with less positive skewness than the other analyzed species $\left(c_{w}=1.47-2.10\right)$. The results for Coniferous trees of Ts, Af and Pd were approximately coincident with those in warm-

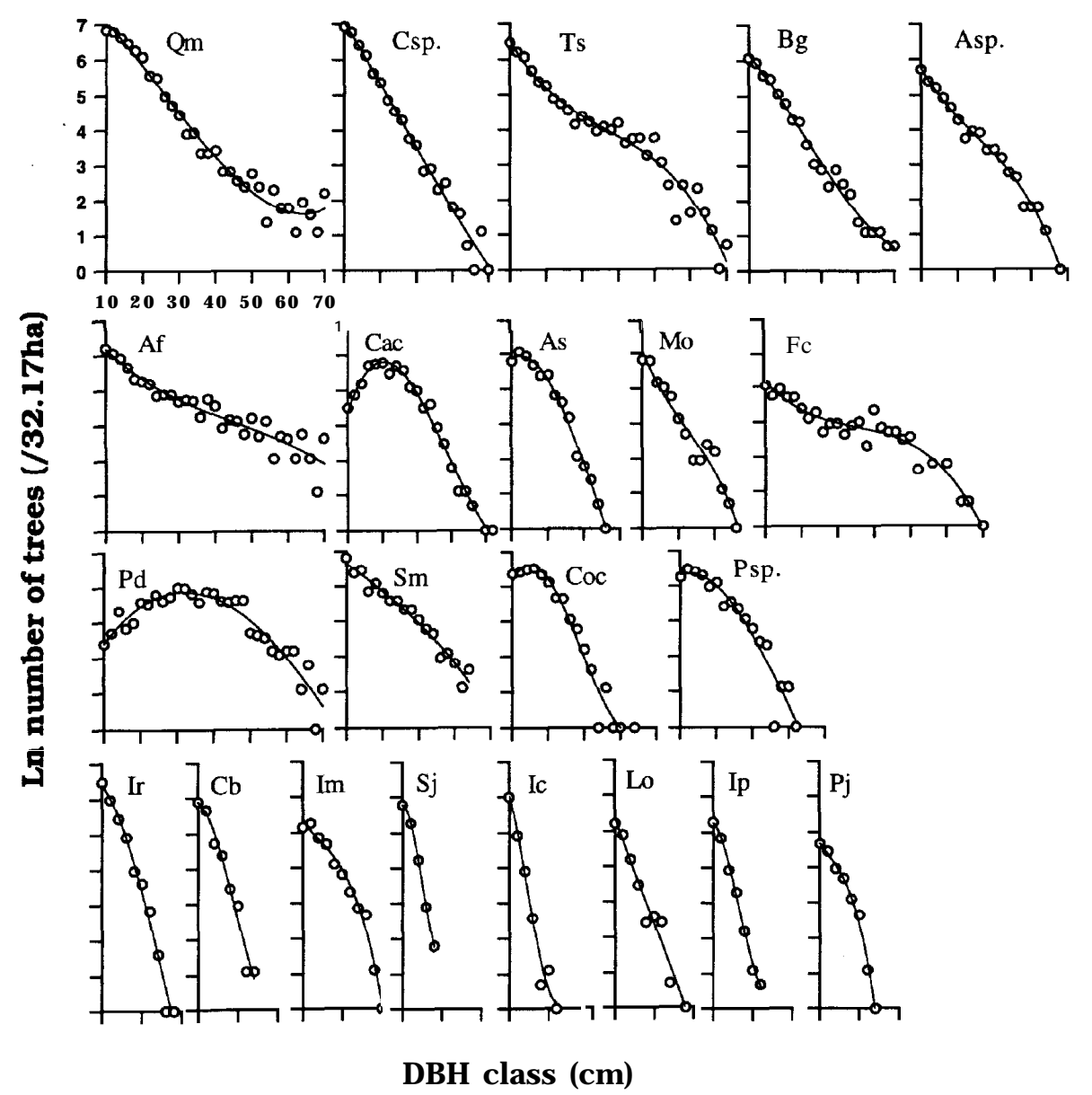

Fig. 5. DBH distribution for each species at forest level. Fitted lines, by eq. 2. 
Table 2. Attributes of each tree species at forest level.

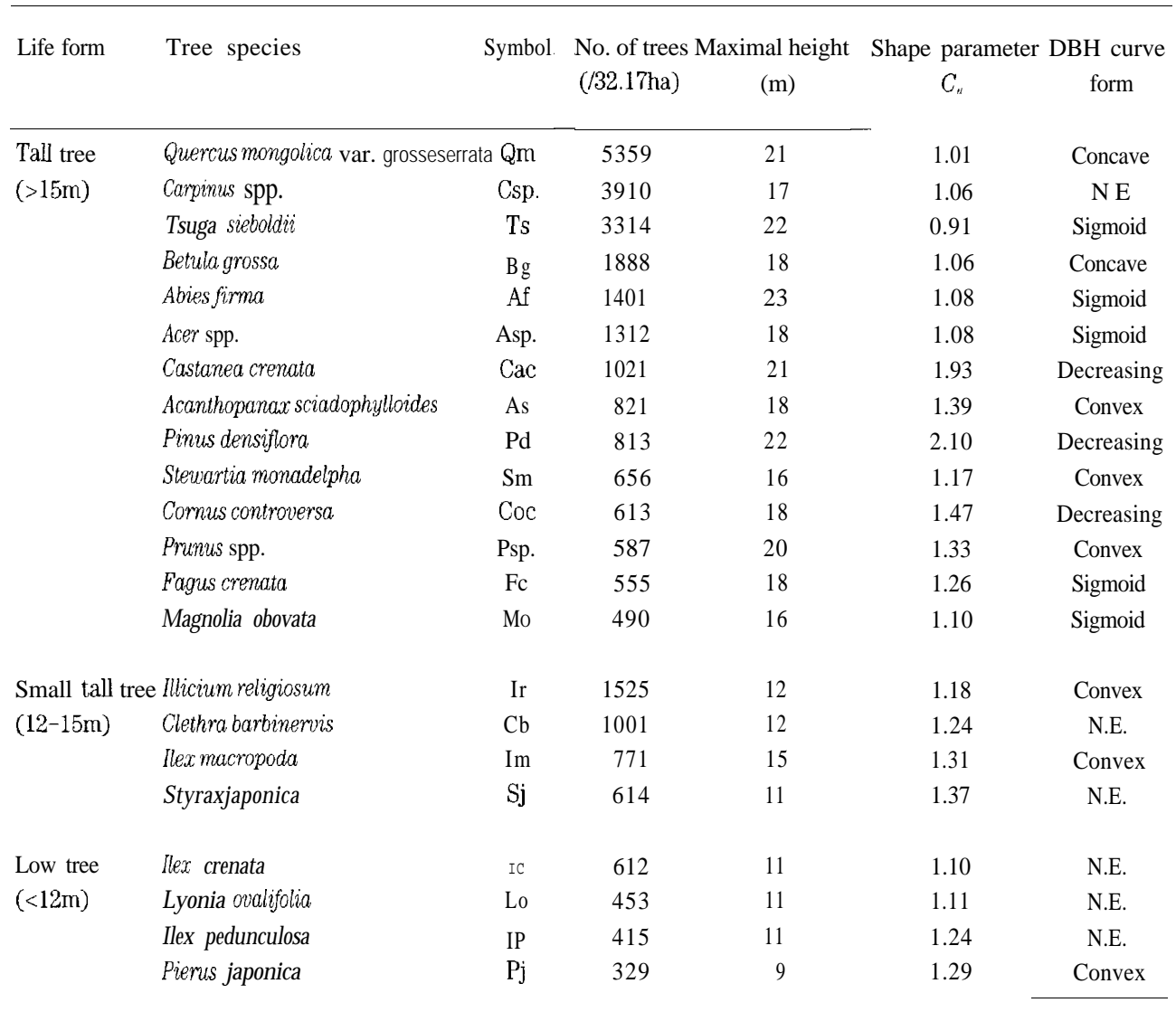

temperate forests of 1-100 ha order (Suzuki, 1984). As West et al. (1981) suggested, the shape of DBH distribution for a given tall tree species at forest level was roughly related to the tolerance characteristics. In short, the distributions for shade-intolerant species such as Cac, Pd and Psp. were decreasing or convex, while the distributions for shadetolerant species such as $\mathrm{Ts}$, Af and $\mathrm{Fc}$ were sigmoid shape. Decline pattern of tree density at middle-size $(22-30 \mathrm{~cm}$ in DBH) and large-size $(>30 \mathrm{~cm})$ with DBH class was thought to reflect degree of shade-tolerance of species, although not strictly speaking.

DBH distribution for each tall tree, except for Sm, at forest level was compared with that within small-scale stands of different mean DBH (Harcombe and Marks, 19'78; Kikuzawa and Asai, 1979; Kakihara, 1980; Aiba et al., 1983; Kikuzawa, 1984; Ninomiya et al., 1985; Higo et al., 1987; Komiyama, 1989; Yuruki and Setsu, 1992; Kunisaki and Imada, 1996). Twelve of fourteen species showed approximately similar shape between stands of different spatial scale, but the shape of the distribution for Qm and Bg differed between 
the stands. In small-scale stands, it has been reported that $\mathrm{Qm}$ and $\mathrm{Bg}$ mostly show unimodal shape (Kikuzawa and Asai, 1979; Aiba et al., 1983; Komiyama, 1989; Yuruki and Setsu, 1992), and skewness of the distribution for Qm become less with stand development (Kakihara, 1980; Kikuzawa, 1984). Therefore, concave distribution for Qm at forest level was thought to be constituted from unimodal distributions within smallscale stands varying in development stage.

On the other hand, small-tall and low tree species, whose matured trees have less height than $15 \mathrm{~m}$ and seldom grow up to the top canopy of stands, were assigned to two of five categories; negative exponential and convex. Each species had a steep decline of tree density with $\mathrm{DBH}$, and the value of $c_{u}$ was from 1.04-1.37. Analyzed small-tall and low trees have the vigorous ability of flushing sprouts (Shima et al., 1989; Tanimoto, 1990; Yuruki and Setsu, 1992; Ito and Aragami, 1993), and Ir, Ic, Ip and Pj are also shadetolerant trees (Tanimoto, 1990). These characteristics was thought to indicate that tree individual receives no benefit due to large-size stems, because the individual can maintenance itself under the canopy layer by turning over new stems instead of damaged and died stems, and/or by utilizing less light resource efficiently. In conclusion, we proposed a hypothesis that shape of DBH distribution for these mid- and understory species at forest level is related to the tolerance and sprouting characteristics.

\section{ACKNOWLEDGEMENTS}

Authors thank Dr. K. Aragami and the members of the Kyushu University Forests for permitting the use of yield inventory data. we also thank Dr. T. Masutani for his critical advice against our primary idea on this study.

\section{REFERENCES}

Aiba, Y., K. Haibara, S. Tamaki, M. Arai and T. Aizawa 1983 Stand structure of a former coppice forest in north Kanto region. Bull. Univ. For. Tokyo Univ. Agr.\& Tech., 19: 9-20 (in Japanese with English summary)

Aragami, K. 1987 Studies on the process of formation of Abies and Tsuga natural forest in the central mountainous district of Kyushu. Bull. Kyushu Univ. For., 57: 17-108 (in Japanese with English summary)

Bailey, R. L. and T. R. Dell 1973 Quantifying diameter distribution with the weibull function. For. Sci., 19 : 97-104

DeLiocourt, F. 1898 De l'amenagement des Sapinieres. Bull. Soc. For. Franch-Conte Belfort, Besancon, pp. $396-409$

Goff, F. G. and D. West 1975 Canopy-understory interaction effects on forest population structure. For. Sci., 21: 98-108

Harcombe, P. A. and P. L. Marks 1978 Tree diameter distributions and replacement processes in southeast Texas forests. For. Sci., 24: 153-166

Higo, M., S. Fujimoto, R. Shibakusa, T. Igarashi and S. Funakoshi 1987 Growth and successional changes of deciduous broad-leaved forest stands disturbed by the 15th Typhoon in 1954. (I) A preliminary report on the results obtained in 30) years after damaged. Bull. Hokkaido Univ. For., 44: 123-138 (in Japanese with English summary)

Higo, M. and T. Teramoto 1989 Stand structure and dynamics of cool temperate broad-leaved forest 
dominated by Quercus mongolica var. grosseserrata. Bull. Fac. Agr. GifuUniv., 54: 51-58 (in Japanese with English summary)

Hough, A. F. 1932 Some diameter distributions in forest stands of northwestern Pennsylvania. J.For., 30: 933-943

Ishibashi, S. 1990 Studies on the structural dynamics of natural forest based on a simulation model. Bull. Tokyo Univ. For., 82: 11-101 (in Japanese with English summary)

Ito, S. and K. Aragami 1993 Comparisons of forest structure between different stages of forest succession in cool temperate mixed forests. Sci. Bull. Fac.Agr.Kyushu Univ., 47: 195-202 (in Japanese with English summary).

Kakihara, M. 1980 Analysis of broad-leaved natural stand in eastern Hokkaido IV: Diameter distribution of Quercus crispula natural stand. Trans. 91st Mtg. Jpn. For. Soc., pp. $75-76$ (in Japanese)

Kakihara, M. 1995 A study on the Weibull parameter expressing the diameter distribution of plantations. Bull. Kyushu Univ. For., 72: 1-10

Kikuzawa, K. 1984 Growth of young deciduous broad-leaved forest stands regenerating after fire. BULL. Hokkaido For. Exp. Stat., 22: 11-17 (in Japanese with English summary)

Kikuzawa, K. and T. Asai 1979 Structure and growth of a deciduous hardwood forest stand at Hidaka district, in Hokkaido. Bull. Hokkaido For. Exp. Stat., 16: 1-17 (in Japanese with English summary)

Kohyama, T. 1986 Tree size structure of stands and each species in primary warn-temperate ram forests of southern Japan. Bot. Mag. Tokyo, 99: 267-279

Komiyama, A. 1989 Tree age composition and the regeneration process of a secondary deciduous broadleaved forest. J. Jpn. For. Soc., 71:374-379 (in Japanese)

Knuchel, H. 1953 Planning and Control in the Managed Forest. O 1 i v e r a n d B o y $360 \mathrm{pp} \Xi \mathrm{d} \mathrm{i} \mathrm{n} \mathrm{b} \mathrm{u} \mathrm{r} \mathrm{g} \mathrm{h} \mathrm{,}$

Kunisaki, T. and M. Imada 1996 Stand structure for middle-aged natural Pinus densiflora forests in the central mountainous district of Kyushu. Jpn. J. For. Plann., 27: (in press) (in Japanese with English summary)

Kunisaki, T., N. Mizoue and M. Imada 1996 Stem growths of canopy and sub-canopy trees in natural Akamatsu (Pinus densiflora) stands. Bull. Kyushu Univ. For., 74: 23-40 (in Japanese with English summary)

Lorimer, C. G. and A. G. Krug 1983 Diameter distributions in even-aged stands of shade-tolerant and midtolerant tree species. Am. Midl. Nat., 109: 331-345

Meyer, H. A. 1952 Structure, growth and dram in balanced unevenaged forests. J. For., 50: 85-92

Minowa, M. and Y. Hirata 1993 A modified exponential distribution for describing the stand structure of uneven-aged forests. J.Jpn. For. Soc., 75: 449-451

Ninomiya, I., E. Tomita, A. Tsujita and K. Ogino 1985 Diversity of species composition and stand structure in a natural secondary Fir-Hemlock forest. Bull. Ehime Univ. For., 23: 59-76 (in Japanese with English summary)

Parker, A. J. 1988 Stand structure in subalpine forests of Yosemite Natural Park, California. For. Sci., 34: $1047-1058$

Schmelz, D. V. and A. A. Lindsey 1965 Size-class structure of old-growth forests in Indiana. For. Sci., 11 : 258-264

Setsu, T. 1990 Regeneration of cutover deciduous forest. Trans. Mtg. Kyushu Br. Jpn. For. Soc., 43:1920 (in Japanese)

Shima, K., S. Katagiri and N. Kaneko 1989 Dynamics of sprout shoots during the two years after cutting a Konara (Quercus serrata) secondary forest. J.Jpn. For. Soc., 71: 410-416 (in Japanese)

Suzuki, E. 1984 Regeneration of Abies firma and Tsuga sieboldii mixed stands in warm-temperate forests. Iden, 38: 56-61 (in Japanese)

Tanimoto, T. 1990 Ecology and Management of Hardwood Forests. Soubun-sha, Tokyo, 245pp. (in Japanese)

Tanouchi, H. and S. Yamamoto 1991 Floristic composition and structure in an old-growth evergreen broad-leaved forest at the Aya district, southern Kyushu. Trans. 102nd Mtg. Jpn. For. Soc. pp. 409410 (in Japanese)

The Kyushu University Forests 1996 5th Report for Forest Operation Plan of the University Forest in Miyazaki. (in Japanese)

Wada, S. and N. Nakagoshi 1994 The structure and succession of temperate forests. Trans. 105th Mtg. 
Jpn. For. Soc.pp. 271-274 (in Japanese)

West, D. C., H. H. Shugart, JR. and J. W. Ranney 1981 Population structure of forests over a large area, For. Sci, 27: 701-710

Yuruki, T. and T. Setsu 1992 Development of a secondary deciduous broad-leaved forest in the central mountainous district of Kyushu. Bull. Kyushu Univ. For., 66: 1-18 (in Japanese with English summary) 